$\underset{1}{d}$

CHOICE

Correspondence to

Dr Richard A Stein, Department of Molecular Biology, Lewis Thomas Lab 320, Princeton University, Princeton, NJ 08544 . USA; ras2@princeton.edu

Accepted 20 June 2011 Published Online First

1 November 2011

\title{
Epigenetics and environmental exposures
}

\author{
Richard A Stein
}

\section{ABSTRACT}

It is becoming increasingly apparent that genetic factors are inadequate to fully explain many processes that shape development and disease. For example, monozygotic twin pairs, despite sharing identical DNA sequences, are often discordant for many traits and diseases, indicating that the same genotype can give rise to distinct phenotypes. This points towards the involvement of additional factors that cannot be explained solely by the sequence of the genome. Epigenetic modifications, defined as heritable changes that do not alter the nucleotide sequence, emerge as key factors that regulate chromatin structure and gene expression and, together with genetic factors, provide the mechanistic basis to understand the biological effects of various classes of environmental exposures. Epigenetic mechanisms explain the ability of certain chemical compounds to initiate biological perturbations that can lead to malignancy, despite being weak mutagens or lacking mutagenic activity altogether-a view that challenges old beliefs and opens new avenues in public health. The field of epigenetics also explains the causal link between certain infectious diseases and cancer, a relationship that was first observed over a century ago and was initially discounted, then fell into oblivion and more recently re-emerged as an important concept in biology. A key feature that distinguishes epigenetic modifications from genetic changes is their reversible nature. This provides exciting prophylactic and therapeutic perspectives, some of which already materialised with the approval of the first drugs that modulate the epigenetic machinery, reinforcing the idea that our genes are not our destiny.

The human genome provided an invaluable and long-awaited glimpse into the relationship between genotype and phenotype. However, as links between mutations and disease predisposition were unveiled, it also became apparent that significant phenotypic discordance exists even among monozygotic twins, which are genetically identical. ${ }^{1} 2$ This pointed towards the involvement of additional factors that shape the phenotype and cannot be explained by DNA sequence variation alone.

Chromosomal changes that are heritable, but do not involve alterations in the DNA sequence, are known as epigenetic modifications. Unlike the genetic profile, which is identical among the cells within an organism, the epigenetic profile is highly dynamic and reversible, and varies among cells in the same organism and, in the same cell, between various states, such as health versus disease, or in response to environmental perturbations. ${ }^{3}$

In a comparison between monozygotic twin pairs, Fraga et $a l^{4}$ found that epigenetic modifications, such as DNA methylation and histone acetylation, became increasingly divergent with age.
This explained that gene expression profiles, although almost identical between 3-year-old twin pairs, became very different by age 50 , illustrating that the phenotype, even in genetically identical individuals, is differentially sculptured by epigenetic marks during their lifetimes. In the first longitudinal study to examine epigenetic changes during childhood, Wong et at $t^{5}$ examined three promoter regions in monozygotic and dizygotic twin pairs at ages 5 and 10 and found highly discordant DNA methylation levels that changed in time even between genetically identical individuals. These findings underscore the need to better understand epigenetic modifications that, together with genetic factors, shape gene expression and biological processes.

\section{EPIGENETIC MODIFICATIONS}

Three classes of epigenetic modifications were described: DNA methylation, post-translational histone modifications and non-coding RNA-mediated signalling pathways. DNA methylation at CpG dinucleotides, the most frequent epigenetic change described to date in vertebrates, involves the covalent attachment of a methyl group to position five of cytosine to generate 5 -methyl cytosine. ${ }^{6}$ The methyl group protrudes into the major groove of the double-stranded DNA and can recruit protein complexes that post-translationally modify histones, compacting the chromatin and silencing genes, or can displace transcription factors that bind DNA. ${ }^{7}$ CpG-rich regions exist in the promoters of $\sim 60 \%$ of RNA polymerase II transcribed human genes, ${ }^{6}$ where they are unmethylated, and in repetitive genomic sequences, where they are heavily methylated. CpG hypermethylation at promoter regions leads to loss of function, while global hypomethylation at repetitive sequences causes genomic instability. Both types of modification were implicated in cancer development and progression.

The second class of epigenetic changes involves the post-translational modification of the 15-30 amino acid N-terminal unstructured histone tails. These modifications, which include methylation, acetylation, phosphorylation, ADP-ribosylation and ubiquitylation, alter chromatin condensation. ${ }^{7}$ Histone modifications, and the complex combinatorial patterns that they generate, extend the information that can be encoded in the genome, a concept that became known as 'the histone code'.

Regulatory pathways mediated by small noncoding RNA molecules, collectively known as RNA interference, represent the third class of epigenetic modifications. RNA interference can be mediated by exogenous RNA molecules, which are known as small interfering RNAs or siRNA, or by endogenous RNA molecules, known as microRNAs or miRNA. ${ }^{3}$ 
miRNAs are 19-25 nucleotide long non-coding RNA molecules that bind to the $3^{\prime}$ untranslated region of mRNA molecules, and by suppressing mRNA translation or enhancing their degradation, they negatively control gene expression at the post-translational level. ${ }^{3}$ Over 1000 miRNAs were identified in the human genome. Each of them is thought to have several targets, and each target is probably regulated by multiple miRNAs. ${ }^{8}$ Some miRNAs act as oncogenes, while others function as tumour suppressor genes, and many of them are altered in human malignant tumours. 89

\section{ENVIRONMENTAL CHANGES AND EPIGENETIC MODIFICATIONS}

For a long time, it was assumed that chemicals are able to cause cancer only by mutating the DNA. However, a growing body of scientific evidence reveals that this 'carcinogenesis equals mutagenesis' paradigm is not accurate. Twenty years ago, Ashby and Tennant ${ }^{10}$ examined 301 chemicals tested by the US National Toxicology Program and found that from $162(53 \%)$ that were carcinogens, 64 (40\%) were not genotoxic, illustrating the importance to focus on carcinogenic mechanisms other than genotoxicity. For many environmental agents, it is becoming increasingly clear that biological perturbations leading to cancer may occur even in the absence of mutagenesis, via epigenetic changes. Epigenetic changes are clinically relevant in ways that years ago seemed unimaginable. For example, Nobeyama et al ${ }^{11}$ found that tissue factor pathway inhibitor-2, encoding a protein that suppresses the invasiveness of malignant melanoma, was methylated in $29 \%$ of metastatic lesions but in none of the primary tumours examined. This pointed towards gene expression and phenotypic differences between metastatic tumours and the primary tumour they originated from, a finding that presents significant therapeutic applications.

\section{ENDOCRINE DISRUPTORS}

Bisphenol-A (BPA) is an oestrogenic endocrine disruptor and one of the most widely used chemicals worldwide. As a synthetic polymer, BPA has found wide industrial applications, to manufacture polycarbonate plastics used in bottles and containers that store food and drinks, and epoxy resins that coat food cans. Monomers can leak into food or drinks during heating, under the action of acids or bases, or upon decay. ${ }^{12}$ A study on 394 adults in the USA detected BPA in $95 \%$ of the urine samples at concentrations $>0.1 \mu \mathrm{g} /$ litre, ${ }^{13}$ and a study conducted in Mexico City found that $80 \%$ of the pregnant women examined had detectable urinary BPA at concentrations between $<0.4$ and $6.7 \mu \mathrm{g} /$ litre, and women who delivered $\leq 37$ weeks of gestation had higher urinary BPA levels than those who delivered after 37 weeks. ${ }^{14}$

An informative animal model, the Agouti viable yellow $\left(A^{v y}\right)$ mouse, provides an excellent tool to examine epigenetic changes caused by environmental and nutritional exposures and was valuable in understanding the effects of BPA. In this model, a retrotransposable element, known as intracisternal A particle (IAP), is inserted upstream from the transcriptional start site of the Agouti allele, which encodes the yellow pigment responsible for the fur colour. Transcription of the Agouti gene normally initiates from a hair cycle-specific promoter and occurs for a very limited time during the follicle growth cycle, and the yellow pigment gives, on the black hair background, the brown or agouti coat colour. The $A^{v y}$ metastable allele can undergo epigenetic modifications in response to environmental perturbations, and as a result, the gene becomes differentially expressed in genetically identical individuals. ${ }^{15}{ }^{16}$ A cryptic promoter within the retrotransposable element contains several CpG sites, and their methylation is inversely related to the expression level of the yellow pigment. When these sites are hypermethylated, pigment expression occurs only in hair follicles and at low levels, just like in wild-type mice, but when they are hypomethylated, expression becomes constitutive and occurs in all tissues, and is responsible for the yellow fur colour. In addition, ectopic expression of the pigment also increases susceptibility to obesity, diabetes and cancer. ${ }^{16}$

By using this model, Dolinoy et al ${ }^{15}$ showed that maternal BPA exposure can establish stable epigenetic alterations in the form of hypomethylation at nine distinct $\mathrm{CpG}$ sites upstream of the $A^{v y}$ IAP cryptic promoter and change the phenotype in the offspring, with a shift of the fur colour towards yellow. DNA methylation at this locus was similar in tissues originating from the three germ layers, indicating that epigenetic patterning is sensitive to BPA exposure during early development.

Additional studies reported that BPA causes epigenetic changes in several cell types. Yaoi et $a l^{17}$ surveyed the methylation of approximately 2500 chromosomal loci to examine the impact of low-level ( $20 \mu \mathrm{g} / \mathrm{kg}$ of body weight) BPA exposure on the developing murine forebrain and found changes in signal intensity at 48 sites (1.9\%). Certain spots were specifically induced at days 12.5 or 14.5 during development, while others showed changes at both stages, indicating that maternal exposure to BPA can establish epigenetic changes at various chromosomal loci and at specific times during development. Weng et a $^{18}$ reported gene silencing mediated by CpG promoter methylation in breast epithelial cells exposed to low BPA levels $(4 \mathrm{~nm})$ and provided the first piece of evidence that interindividual differences in susceptibility to low-dose BPA may exist in humans, and Prins et al (2008) found that low doses of BPA $(10 \mu \mathrm{g} / \mathrm{kg}$ of body weight/day), comparable to those measured in the blood of human fetuses at term, increased the susceptibility to preneoplastic prostate changes during ageing by epigenetic mechanisms. ${ }^{19}$

Methylation changes are not the only epigenetic mechanism reported for BPA. In two placental cell lines derived from the first trimester villous and extravillous cells, Avissar-Whiting et al ${ }^{20}$ found 25 miRNAs differentially expressed in one cell line, 60 differentially expressed in the second one and 21 miRNAs in common between the two sets, in response to BPA exposure. One miRNA overexpressed in both cell lines, miR-146a, is known for its involvement in several malignant tumours. No miRNAs were significantly changed in a third cell line, derived from terminally differentiated third trimester extravillous cells, indicating that these epigenetic perturbations only occur during a specific time of embryonic development.

Additional endocrine disruptors cause epigenetic modifications. Newbold et $a l^{21}$ found, in a mouse model, significant uterine gene expression changes after neonatal diethylstilbestrol (DES) exposure, and Tang et $a l^{22}$ reported that neonatal DES exposure epigenetically reprograms nucleosomal binding protein 1 expression and its interaction with ovarian hormones in adulthood, providing a fascinating glimpse into the two-step early life reprogramming of adult diseases. Some endocrine disruptors have transgenerational effects. Vinclozolin, a fungicide with antiandrogenic activity, was shown to affect promoter methylation in the rat sperm epigenome for three generations after exposure, ${ }^{23}$ and a significantly higher proportion of boys born to daughters with in utero DES exposure had hypospadias compared to boys born from unexposed mothers. ${ }^{24}$

Epigenetic changes caused by endocrine disruptors are important, particularly as several studies document a decline in 
reproductive health, in several locations worldwide, that started in the middle of the 20th century, coincided with an $>20$-fold increase in the use of natural and synthetic chemicals and cannot be solely explained by genetic factors. ${ }^{25}$

\section{METALS}

With the exception of chromium, which forms DNA adducts, most carcinogenic metals are weak mutagens and act by epigenetic mechanisms. ${ }^{26}$ Nickel compounds, linked to occupational and environmental exposures, have carcinogenic effects despite not being a known mutagen. ${ }^{27-29}$ In vitro and in vivo experiments reveal that nickel compounds silence gene expression by methylating DNA, an effect explained by the ability of $\mathrm{Ni}^{2+}$ to substitute $\mathrm{Mg}^{2+}$ in the DNA phosphate backbone and increase chromosome condensation. ${ }^{26} 29$ This establishes heterochromatin regions where the access of cellular proteins to the respective genomic segments becomes more difficult. When the silenced regions contain genes relevant to cancer initiation or progression, such as tumour suppressor genes or senescence genes, their inactivation may lead to disease. ${ }^{29}$

Nickel compounds also induce global post-translational histone modifications. Golebiowski and $\mathrm{Kasprzak}^{30}$ reported decreased acetylation of histones $\mathrm{H} 2 \mathrm{~A}, \mathrm{H} 2 \mathrm{~B}, \mathrm{H} 3$ and $\mathrm{H} 4$ in a time-dependent and concentration-dependent manner in human and rat cell lines upon nickel exposure. Chen et $a l^{28}$ found that at $\leq 1 \mathrm{~mm}$ concentrations, nickel decreased a specific histone demethylase and increased global H3K9 monomethylation and dimethylation in several cell lines. In response to soluble nickel compounds at levels showing minimal cytotoxicity, Ke et $a^{\beta 1}$ described three histone modifications- $\mathrm{H} 3 \mathrm{~K} 9$ dimethylation, increased $\mathrm{H} 2 \mathrm{~A}$ and $\mathrm{H} 2 \mathrm{~B}$ ubiquitylation and reduced acetylation, which was also associated with a transgene silencing.

Cadmium, an occupational and environmental carcinogen linked to several types of human cancer, has very low levels of mutagenicity, and its carcinogenic mechanisms have been elusive for a long time. ${ }^{32}$ Takiguchi et $a l^{33}$ reported that mammalian and bacterial DNA methyltransferases were inhibited in rat liver cells exposed to concentrations of up to $2.5 \mu \mathrm{m}$ cadmium, resulting in concentration-dependent decrease in global DNA methylation after 1 week. More recently, Doi et $a^{34}$ reported that cadmium downregulates two DNA methyltransferases in chick embryos, causing global DNA hypomethylation, a potential explanation for the ventral body wall defects caused by this compound.

Until recently, chromium was thought to cause cancer only through its ability to damage DNA, but epigenetic mechanisms are becoming increasingly apparent. ${ }^{27}$ Klein et $a^{35}$ reported for the first time that potassium chromate, a carcinogen, causes aberrant DNA methylation and silences a reporter gene in a mammalian cell line. Ali et $a l^{36}$ found increased aberrant methylation in the promoters of three tumour suppressor genes in lung cancers of chromate workers compared to non-chromate lung cancer controls, and concordant methylation of multiple loci was more often observed among chromate workers. Sun et $a l^{37}$ found that hexavalent chromium, at $5-10 \mu \mathrm{m}$ concentrations, establishes global and local, gene-specific histone methylation changes in lung cancer and in non-cancerous bronchial epithelial cells.

In the first study to examine the link between maternal lead burden and genomic DNA methylation from the cord blood, Pilsner et $a l^{38}$ found that lead levels in the patella and the tibia, which reflect cumulative exposure, were inversely related to the cord blood methylation levels of the long interspersed nuclear element-1 (LINE-1) and AluI repetitive sequences global methylation markers, respectively. The authors did not find a correlation between DNA methylation and cord blood lead levels, which reflect recent exposure.

\section{BENZENE, POLYCYCLIC AROMATIC HYDROCARBONS AND PERSISTENT ORGANIC POLLUTANTS}

Benzene and aromatic hydrocarbons have increasingly emerged as environmental hazards in occupational or non-occupational settings. In the first study to link low levels of a common environmental carcinogen to epigenetic changes in human cancers, Bollati et $a l^{39}$ examined traffic police officers and gas station attendants from Milan, Italy and reported that low-level airborne benzene exposures that are common in western countries cause a dose-dependent global hypomethylation in the LINE-1 and AluI repetitive sequences. In addition, the authors described hypermethylation and hypomethylation at specific promoters known to undergo epigenetic changes in human cancers.

As a group of chemicals, polycyclic aromatic hydrocarbons (PAHs) include thousands of compounds ubiquitously distributed in the environment. An interesting fact about PAHs is that for many years, the focus was on their ability to cause genotoxic damage while their potential to induce epigenetic modifications was largely ignored. ${ }^{40}$ Benzpyrene, a prototype PAH, is an environmental and occupational carcinogen found in vehicle emissions and in cigarette smoke. In the first study showing that benzpyrene causes epigenetic changes, Sadikovic et al li $^{41}$ conducted a genome-wide analysis of benzpyrene-treated cells and found 775 genes that were hypoacetylated and 1456 that were hyperacetylated after exposure. Many of the affected genes had fundamental cellular roles in processes including DNA replication, repair and carcinogenesis.

Cigarette smoke is a complex mix of over 4000 chemicals. In one of the first studies linking in utero tobacco exposure to DNA methylation changes in the offspring, Breton et al ${ }^{42}$ found two genes, encoding a receptor tyrosine kinase important for cell survival and a receptor tyrosine phosphatase important for central and peripheral nervous system development that exhibited consistent methylation changes as a result of maternal smoking. Toledo-Rodriguez et al ${ }^{43}$ found, in adolescents exposed to cigarette smoke in utero, an almost fourfold increased methylation in the promoter and 5 -untranslated region of brain-derived neurotrophic factor, a gene that shapes brain plasticity during development.

In the first study that examined the effects of smoking on miRNA expression, Schembri et al ${ }^{44}$ found 28 miRNAs that were differentially expressed, and $82 \%$ of them downregulated, in smokers. One of these, miR-218, is also downregulated in several cancers, and the authors showed that modulating its levels changed the expression of its target genes. Xi et a ${ }^{45}$ found that cigarette smoke condensate causes an early and significant increase in miR-31 that is apparent within $24 \mathrm{~h}$ after exposure and persists for 20 days after the exposure stops, and Maccani et $a l^{46}$ found that three miRNAs important for growth and development are significantly downregulated in the placenta of smoke-exposed mothers compared to controls.

The first study to link persistent organic pollutant (POP) exposure to DNA methylation in humans found, in a Greenlandic Inuit population, which has one of the highest POP blood levels worldwide, an inverse relationship with the methylation of LINE-1 and Alu repetitive elements. This finding opens important questions with regard to the epigenetic effects of these compounds. ${ }^{47}$ 


\section{DIET}

Studies have long indicated that adversity during development shapes the risk of adult-onset disease decades later, a concept that became known as the developmental origins of health and disease or the Barker Hypothesis. The impact of nutritional influences during development on disease risk later in life was studied extensively as a result of a sad period in history, the Dutch Hunger Winter, a period of abrupt and intense famine that affected the western part of the Netherlands at the end of World War II. Heijmans et a ${ }^{48}$ found that individuals who were nutritionally deprived in very early stages of development showed, six decades later, lower DNA methylation levels in IGF2, an imprinted gene with key roles in growth and development, than their same-sex, unexposed sibling. These differences were not found in individuals exposed to famine late during gestation, indicating that epigenetic changes might be particularly sensitive during early development.

Xiang et $\mathrm{al}^{49}$ reported that selenium, an essential trace element that protects against several types of human cancer, but may also negatively affect DNA integrity after unregulated intake, can epigenetically restore the expression of several tumour suppressor genes that were silenced by hypermethylation.

Recent findings also promise to unveil the teratogenic mechanisms of alcohol, a major cause of non-genetic developmental delay. Zhou et al ${ }^{50}$ conducted a genome-wide methylation analysis on neural stem cells exposed to alcohol and, for the first time, revealed significant changes in the promoter methylation pattern and in neural stem cell migration and differentiation, indicating that alcohol exposure alters epigenetic programming during neural stem cell development.

Ichi et $a l^{51}$ found that folic acid establishes epigenetic changes in Hes1 and Neurog2, two genes involved in the development of the murine nervous system. Folic acid fortification, a public health accomplishment, reduced the incidence of neural tube defects, and many studies documented a $20-40 \%$ decrease in the colorectal cancer risk among individuals with the highest folate intake. At the same time, an emerging concept is that folic acid could also have unintended consequences by inducing epigenetically mediated changes during development, ${ }^{52}$ and several studies reveal that it accelerates the growth of already existing tumours, pointing towards a dual modulatory effect, depending on dose and timing. ${ }^{53}$ This underscores the need to better understand the interface between epigenetics, genetics and nutrition.

Even though epigenetic changes caused by chemicals and food are studied separately, Lee et $a l^{54}$ point out that, particularly in context of the large numbers of chemicals present in the food chain, and the potential for synergistic interactions, these two classes of environmental factors cannot be separated from each other, and their impact should be studied together.

\section{INFECTIOUS DISEASES}

Microorganisms were causally implicated in slightly over $20 \%$ of all human cancers. Viruses (hepatitis B, papilloma and the Epstein-Barr virus), bacteria (certain Helicobacter pylori serotypes) and parasites (Schistosoma haematobium) are among the most important pathogens linked to carcinogenesis. The mechanistic links between microorganisms and cancer have been elusive for many years, but recent findings reveal that many pathogens cause epigenetic reprogramming in host cells.

Maekita et al ${ }^{55}$ found increased methylation at several CpG islands in the gastric mucosae of individuals infected with $H$. pylori compared to uninfected individuals. Mongolian gerbils experimentally infected with $H$. pylori exhibited hypermethylation at several promoters from the gastric mucosa. ${ }^{56}$ Methylation levels started to increase $5-10$ weeks after the start of the infection, reached high levels by 50 weeks and decreased 10-20 weeks after the infection was eradicated but remained higher than in uninfected animals. ${ }^{57}$ Cyclosporin $\mathrm{A}$, which suppresses inflammation without affecting bacterial colonisation, abolished this aberrant methylation, indicating that it is not the pathogen itself, but the inflammatory process, that is responsible for the hypermethylation. ${ }^{56}$ Methylation appears to consist of a permanent component that occurs in gastric stem cells and a temporary component that results from methylation in progenitor and differentiated cells. It is thought that the temporary component is the one that disappears after eradicating the infection. ${ }^{57}$

Nakajima et a ${ }^{59}$ demonstrated, for the first time, the existence of gene specificity in the DNA hypermethylation induced by infection. Methylation of specific genes that occurs in a significant number of cells in the mucosa establishes an 'epigenetic field for cancerisation' or 'epigenetic field defect', marking a site with high risk for subsequent malignant transformation. ${ }^{58}$ Epigenetic fields for cancerisation were also described for other tumours, including breast, colon and liver cancer. In some malignant tumours, such as stomach cancer, the inactivation of genes appears to occur more frequently by epigenetic mechanisms, such as aberrant methylation, than by genetic mechanisms. ${ }^{60}$

\section{PHYSICAL AGENTS: UV RADIATION}

Nandakumar et al ${ }^{61}$ showed, for the first time, that chronic exposure to UV-B in mice increases the expression and the activity of DNA methyltransferases, leading to aberrant DNA hypermethylation, which could stimulate other epigenetic mechanisms, such as histone modifications, that culminate in carcinogenesis. This revealed that the silencing of tumour suppressor genes could be involved in the pathogenesis of skin cancers.

\section{SOCIAL INFLUENCES}

Social influences, acting through hormone signalling pathways, are one of the most recent additions to the group of environmental factors that induce epigenetic changes. Weaver et al ${ }^{62}$ compared rats engaged in high versus low licking and grooming (LG) and arched-back nursing ( $\mathrm{ABN}$ ), two types of maternal behaviour that are apparent during the first week after the pups are born, and showed that these maternal tactile influences establish epigenetic changes at the glucocorticoid receptor in the offspring hippocampus.

Exon $1_{7}$ in the rat hippocampal glucocorticoid receptor promoter contains the binding site for nerve growth factorinducible protein A (NGFI-A). Weaver et al ${ }^{62}$ found that the CpG dinucleotide from site 16 within this exon, which is the NGFI-A binding site, is rarely methylated in pups born to mothers with high $\mathrm{LG}-\mathrm{ABN}$ but is always methylated in pups born from mothers with low LG-ABN. In pups born to high LG-ABN mothers, these methylation changes were associated with increased histone H3K9 acetylation and higher NGFI-A binding to the glucocorticoid receptor promoter. Cross-fostering generated a methylation pattern reflecting the rearing mother's behaviour. For the first time, this revealed that maternal care establishes epigenetic marks that shape chromatin organisation and gene expression in the offspring. Subsequent research found that differences in maternal care establish epigenetic changes over broad genomic areas that involve both coding and noncoding regions in the adult rat hippocampus. ${ }^{63}$ 
In the first study to reveal protein synthesis changes in individuals who committed suicide, McGowan et al ${ }^{64}$ found rRNA promoter hypermethylation and decreased rRNA expression in the hippocampus of individuals with a history of abuse or serious neglect, compared to individuals who died accidentally or committed suicide but did not have a history of abuse or neglect. Methylation levels in the hippocampus were not significantly correlated with those in the cerebellum, indicating that hypermethylation was specific to the hippocampus, and supporting the idea that early life adversity exerts specific epigenetic changes in the nervous system.

Roth et $a l^{65}$ found that in rats, psychosocial stress comparable to human post-traumatic stress disorder (PTSD) increased Bdnf methylation in the dorsal hippocampus and downregulated its mRNA in the dorsal and ventral hippocampus, but not in other PTSD-relevant regions. This study, for the first time, linked traumatic stress during adulthood to region-specific epigenetic changes in $B d n f$ and revealed that DNA methylation remains an active process that can be shaped by environmental factors in the adult nervous system.

\section{EPIGENETICS AND PUBLIC HEALTH}

While recent years witnessed significant progress in understanding the biological impact of environmental exposures, an important take-home lesson is the insufficient attention that epigenetic factors have received, relative to genetic ones. Interdisciplinary efforts should increasingly focus on unveiling epigenetic mechanisms and pathways that shape development and disease. As epigenetics reveals, many environmental agents that appeared from epidemiological studies to be carcinogens, despite their inability to mutate DNA in vitro, are able to establish biological perturbations by changing chromosome compaction and gene expression. Epigenetic mechanisms emerge as a 'unifying theme' that, in combination with genetic factors, will assume fundamental roles in explaining the biological effects of chemical, physical, biological and social factors. This dynamically expanding field has already started to impact clinical medicine and should become an important instrument for public health and public policy decisions.

Provenance and peer review Commissioned; externally peer reviewed.

\section{REFERENCES}

1. Ballestar E. Epigenetics lessons from twins: prospects for autoimmune diseases. Clin Rev Allergy Immunol 2010;39:30-41.

2. Petronis A. Epigenetics and twins: three variations on the theme. Trends Genet 2006;22:347-50.

3. Reamon-Buettner SM, Borlak J. A new paradigm in toxicology and teratology: altering gene activity in the absence of DNA sequence variation. Reprod Toxicol 2007:24:20-30.

4. Fraga MF, Ballestar E, Paz MF, et al. Epigenetic differences arise during the lifetime of monozygotic twins. Proc Natl Acad Sci U S A 2005;102:10604-9.

5. Wong CC, Caspi A, Williams $B$, et al. A longitudinal study of epigenetic variation in twins. Epigenetics 2010;5:516-26.

6. Ballestar E, Wolffe AP. Methyl-CpG-binding proteins. Targeting specific gene repression. Eur J Biochem 2001;268:1-6.

7. Fazzari MJ, Greally JM. Epigenomics: beyond $\mathrm{CpG}$ islands. Nat Rev Genet 2004;5:446-55.

8. Chuang JC, Jones PA. Epigenetics and microRNAs. Pediatr Res 2007;61:24R-9R.

9. Davidson MR, Larsen JE, Yang IA, et al. MicroRNA-218 is deleted and downregulated in lung squamous cell carcinoma. PLoS One 2010;5:e12560.

10. Ashby J, Tennant RW. Definitive relationships among chemical structure, carcinogenicity and mutagenicity for 301 chemicals tested by the U.S. NTP. Mutat Res 1991;257:229-306.

11. Nobeyama Y, Okochi-Takada E, Furuta J, et al. Silencing of tissue factor pathway inhibitor-2 gene in malignant melanomas. Int J Cancer 2007;121:301-7.

12. Bromer JG, Zhou Y, Taylor MB, et al. Bisphenol-A exposure in utero leads to epigenetic alterations in the developmental programming of uterine estrogen response. FASEB J 2010;24:2273-80.
13. Calafat A, Kuklenyik Z, Reidy J, et al. Urinary concentrations of bisphenol A and 4nonylphenol in a human reference population. Environ Health Perspect 2005;113:391-5

14. Cantonwine D, Meeker JD, Hu H, et al. Bisphenol a exposure in Mexico City and risk of prematurity: a pilot nested case control study. Environ Health 2010;9:62.

15. Dolinoy DC, Huang D, Jirtle RL. Maternal nutrient supplementation counteracts bisphenol A-induced DNA hypomethylation in early development. Proc Natl Acad Sci USA 2007;104:13056-61.

16. Bernal AJ, Jirtle RJ. Epigenomic disruption: the effects of early developmental exposures. Birth Defects Res A Clin Mol Teratol 2010;88:938-44.

17. Yaoi T, Itoh K, Nakamura K, et al. Genome-wide analysis of epigenomic alterations in fetal mouse forebrain after exposure to low doses of bisphenol A. Biochem Biophys Res Commun 2008;376:563-7.

18. Weng YI, Hsu PY, Liyanarachchi S, et al. Epigenetic influences of low-dose bisphenol A in primary human breast epithelial cells. Toxicol Appl Pharmacol 2010;248:111-21.

19. Prins GS, Tang WY, Belmonte J, et al. Perinatal exposure to oestradiol and bisphenol $A$ alters the prostate epigenome and increases susceptibility to carcinogenesis. Basic Clin Pharmacol Toxicol 2008;102:134-8.

20. Avissar-Whiting $\mathbf{M}$, Veiga KR, Uhl KM, et al. Bisphenol A exposure leads to specific microRNA alterations in placental cells. Reprod Toxicol 2010;29:401-6.

21. Newbold RR, Jefferson WN, Grissom SF, et al. Developmental exposure to diethylstilbestrol alters uterine gene expression that may be associated with uterine neoplasia later in life. Mol Carcinog 2007;46:783-96.

22. Tang WY, Newbold RR, Mardilovich K, et al. Persistent hypomethylation in the promoter of nucleosomal binding protein 1 (Nsbp1) correlates with overexpression of Nsbp1 in mouse uteri neonatally exposed to diethylstilbestrol or genistein. Endocrinology 2008;149:5922-31.

23. Guerrero-Bosagna C, Settles M, Lucker B, et al. Epigenetic transgenerational actions of vinclozolin on promoter regions of the sperm epigenome. PLoS One 2010:5:e13100.

24. Kalfa N, Paris F, Soyer-Gobillard M0, et al. Prevalence of hypospadias in grandsons of women exposed to diethylstilbestrol during pregnancy: a multigenerational national cohort study. Fertil Steril 2011:95:2574-7.

25. Woodruff TJ, Schwartz J, Giudice LC. Research agenda for environmental reproductive health in the 21st century. J Epidemiol Community Health 2010;64:307-10.

26. Arita A, Costa M. Epigenetics in metal carcinogenesis: nickel, arsenic, chromium and cadmium. Metallomics 2009;1:222-8.

27. Kasprzak KS, Sunderman FW Jr, Salnikow K. Nickel carcinogenesis. Mutat Res 2003;533:67-97.

28. Chen $\mathbf{H}, \mathrm{Ke} \mathrm{O}, \mathrm{Kluz} \mathrm{T}$, et al. Nickel ions increase histone $\mathrm{H} 3$ lysine 9 dimethylation and induce transgene silencing. Mol Cell Biol 2006;26:3728-37.

29. Ellen TP, Kluz T, Harder ME, et al. Heterochromatinization as a potential mechanism of nickel-induced carcinogenesis. Biochemistry 2009;48:4626-32.

30. Golebiowski F, Kasprzak KS. Inhibition of core histones acetylation by carcinogenic nickel (II). Mol Cell Biochem 2005;279:133-9.

31. Ke 0, Davidson $\mathrm{T}$, Chen $\mathrm{H}$, et al. Alterations of histone modifications and transgene silencing by nickel chloride. Carcinogenesis 2006;27:1481-8.

32. Waalkes MP. Cadmium carcinogenesis. Mutat Res 2003;533:107-20.

33. Takiguchi $\mathbf{M}$, Achanzar WE, Ou W, et al. Effects of cadmium on DNA-(cytosine-5) methyltransferase activity and DNA methylation status during cadmium-induced cellular transformation. Exp Cell Res 2003;286:355-65.

34. Doi T, Puri P, McCann A, et al. Epigenetic effect of cadmium on global de novo DNA hypomethylation in the cadmium-induced ventral body wall defect (VBWD) in the chick model. Toxicol Sci 2011:120:475-80.

35. Klein CB, Su L, Bowser D, et al. Chromate-induced epimutations in mammalian cells Environ Health Perspect 2002;110:739-43.

36. Ali AH, Kondo $\mathrm{K}$, Namura $\mathrm{T}$, et al. Aberrant DNA methylation of some tumor suppressor genes in lung cancers from workers with chromate exposure. $\mathrm{Mol}$ Carcinog 2011:50:89-99.

37. Sun $\mathbf{H}$, Zhou $\mathrm{X}$, Chen $\mathrm{H}$, et al. Modulation of histone methylation and MLH1 gene silencing by hexavalent chromium. Toxicol Appl Pharmacol 2009;237:258-66.

38. Pilsner JR, Hu H, Ettinger A, et al. Influence of prenatal lead exposure on genomic methylation of cord blood DNA. Environ Health Perspect 2009;117:1466-71.

39. Bollati V, Baccarelli A, Hou L, et al. Changes in DNA methylation patterns in subjects exposed to low-dose benzene. Cancer Res 2007;67:876-80.

40. Upham BL, Weis LM, Trosko JE. Modulated gap junctional intercellular communication as a biomarker of PAH epigenetic toxicity: structure-function relationship. Environ Health Perspect 1998;106(Suppl 4):975-81.

41. Sadikovic B, Andrews J, Carter D, et al. Genome-wide H3K9 histone acetylation profiles are altered in benzopyrene-treated MCF7 breast cancer cells. J Biol Chem 2008;283:4051-60

42. Breton CV, Byun HM, Wenten M, et al. Prenatal tobacco smoke exposure affects global and gene-specific DNA methylation. Am J Respir Crit Care Med 2009:180:462-7.

43. Toledo-Rodriguez $\mathbf{M}$, Lotfipour S, Leonard G, et al. Maternal smoking during pregnancy is associated with epigenetic modifications of the brain-derived neurotrophic factor-6 exon in adolescent offspring. Am J Med Genet $B$ Neuropsychiatr Genet 2010;153B:1350-4.

44. Schembri F, Sridhar S, Perdomo C, et al. MicroRNAs as modulators of smokinginduced gene expression changes in human airway epithelium. Proc Natl Acad Sci U S A 2009;106:2319-24. 
45. Xi S, Yang M, Tao $Y$, et al. Cigarette smoke induces C/EBP- $\beta$-mediated activation of miR-31 in normal human respiratory epithelia and lung cancer cells. PLoS One 2010;5:e13764.

46. Maccani MA, Avissar-Whiting M, Banister CE, et al. Maternal cigarette smoking during pregnancy is associated with downregulation of miR-16, miR-21 and miR146a in the placenta. Epigenetics 2010;5:583-9.

47. Rusiecki JA, Baccarelli A, Bollati V, et al. Global DNA hypomethylation is associated with high serum-persistent organic pollutants in Greenlandic Inuit. Environ Health Perspect 2008:116:1547-52.

48. Heijmans BT, Tobi EW, Stein AD, et al. Persistent epigenetic differences associated with prenatal exposure to famine in humans. Proc Natl Acad Sci U S A 2008:105:17046-9.

49. Xiang N, Zhao R, Song G, et al. Selenite reactivates silenced genes by modifying DNA methylation and histones in prostate cancer cells. Carcinogenesis 2008;29:2175-81.

50. Zhou FC, Balaraman $Y$, Teng $M$, et al. Alcohol alters DNA methylation patterns and inhibits neural stem cell differentiation. Alcohol Clin Exp Res 2011;35:1-12.

51. Ichi S, Costa FF, Bischof JM, et al. Folic acid remodels chromatin on Hes1 and Neurog2 promoters during caudal neural tube development. J Biol Chem 2010:285:36922-32

52. Waterland RA, Jirtle RL. Transposable elements: targets for early nutritional effects on epigenetic gene regulation. Mol Cell Biol 2003;23:5293-300.

53. Kim YI. Folate, colorectal carcinogenesis, and DNA methylation: lessons from animal studies. Environ Mol Mutagen 2004;44:10-25.

54. Lee DH, Jacobs DR Jr, Porta M. Hypothesis: a unifying mechanism for nutrition and chemicals as lifelong modulators of DNA hypomethylation. Environ Health Perspect 2009;117:1799-802
55. Maekita T, Nakazawa K, Mihara M et al. High levels of aberrant DNA methylation in Helicobacter pylori-infected gastric mucosae and its possible association with gastric cancer risk. Clin Cancer Res 2006;12:989-95.

56. Niwa T, Tsukamoto T, Toyoda T, et al. Inflammatory processes triggered by Helicobacter pylori infection cause aberrant DNA methylation in gastric epithelial cells. Cancer Res 2010:70:1430-40.

57. Nakajima T, Enomoto S, Ushijima T. DNA methylation: a marker for carcinogen exposure and cancer risk. Environ Health Prev Med 2008;13:8-15.

58. Niwa T, Ushijima T. Induction of epigenetic alterations by chronic inflammation and its significance on carcinogenesis. Adv Genet 2010;11:41-56.

59. Nakajima T, Yamashita S, Maekita $T$, et al. The presence of a methylation fingerprint of Helicobacter pylori infection in human gastric mucosae. Int J Cancer 2009;124:905-10.

60. Ushijima T, Sasako M. Focus on gastric cancer. Cancer Cell 2004;5:121-5

61. Nandakumar V, Vaid M, Tollefsbol TO, et al. Aberrant DNA hypermethylation patterns lead to transcriptional silencing of tumor suppressor genes in UVB-exposed skin and UVB-induced skin tumors of mice. Carcinogenesis 2011;32:597-604.

62. Weaver IC, Cervoni N, Champagne FA, et al. Epigenetic programming by materna behavior. Nat Neurosci 2004:7:847-54.

63. McGowan PO, Suderman M, Sasaki A, et al. Broad epigenetic signature of materna care in the brain of adult rats. PLoS One 2011;6:e14739.

64. McGowan PO, Sasaki A, Huang TC, et al. Promoter-wide hypermethylation of the ribosomal RNA gene promoter in the suicide brain. PLoS One 2008;3:e2085

65. Roth TL, Zoladz PR, Sweatt JD, et al. Epigenetic modification of hippocampal Bdnf DNA in adult rats in an animal model of post-traumatic stress disorder. $J$ Psychiatr Res 2011;45:919-26.

\section{Have confidence in your decision making.}
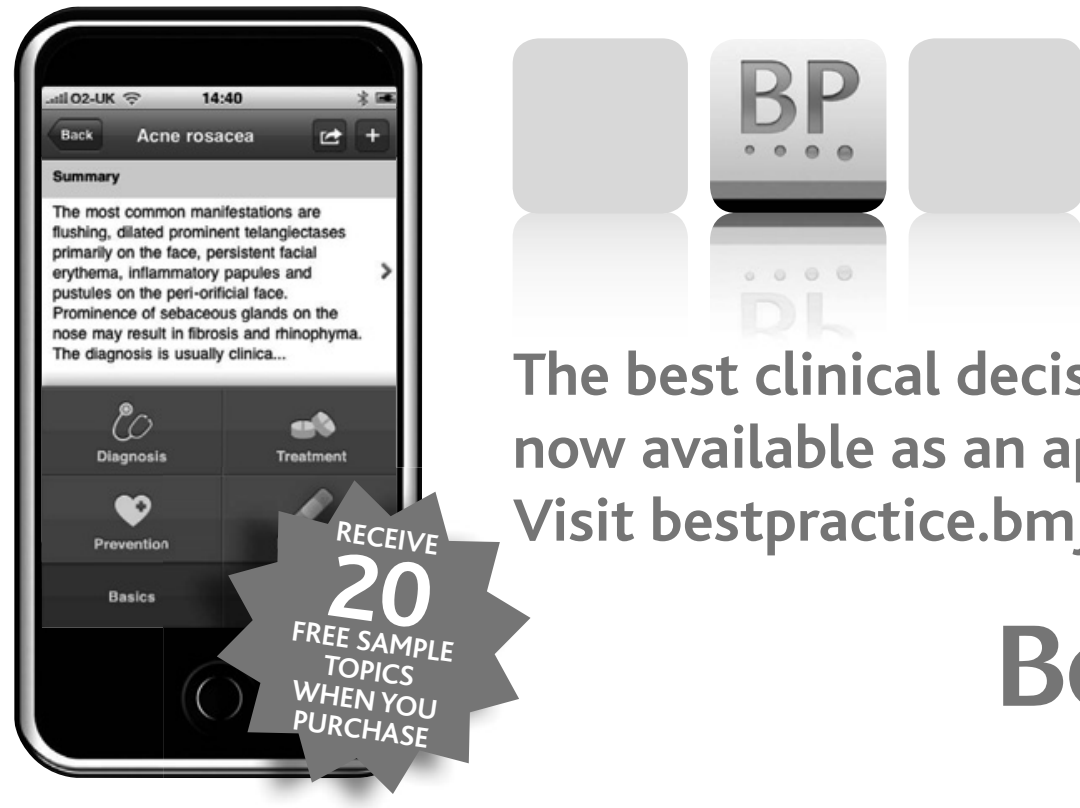

The best clinical decision support tool is now available as an app for your iPhone. Visit bestpractice.bmj.com/app

\section{clinicians $\bullet$ medical students $\bullet$ nurses $\bullet$ healthcare practitioners}

